\title{
ARQUEOLOGIA DAS APRENDIZAGENS NO ALANDROAL: \\ EM BUSCA DAS ESCOLAS FORA DA ESCOLA ${ }^{1}$
}

Bravo Nico

(Universidade de Évora/jbn@uevora.pt)

Lurdes Nico

(Direcção Regional de Educação do Alentejo/lurdes.nico@drealentejo.pt)

Palavras-chave: Contextos de Aprendizagem; Educação Comunitária; Carta Educativa

\section{INTRODUÇÃO}

Em Novembro de 2007, iniciou-se um dos maiores projectos de investigação em Educação, actualmente em curso, na região Alentejo, envolvendo a Universidade de Évora, a Direcção Regional de Educação do Alentejo, a Associação de Desenvolvimento Comunitário SUÃO e o jornal regional Diário do SUL. O projecto de pesquisa, denominado "Arqueologia das Aprendizagens no Alandroal", assumiu, como objectivo, realizar o levantamento e caracterização do universo de aprendizagens disponíveis e concretizadas num concelho (Alandroal), durante a década 1997-2007 (Projecto PTDC/CED/81388/2006, financiado pela Fundação para a Ciência e a Tecnologia). Na presente comunicação, apresentar-se-ão os resultados já disponíveis, particularmente o mapa territorial de todas as oportunidades de aprendizagem existentes em todas as instituições de todas as freguesias do concelho, no período indicado.

\section{O TERRITÓRIO E A APRENDIZAGEM}

Aprende-se em todo o lado, a qualquer momento, em qualquer circunstância, com quem quer que seja e com qualquer objectivo. No território objecto do nosso estudo (Concelho do Alandroal - localizado na região Alentejo, ao Sul de Portugal), como em qualquer outro contexto geográfico, social e cultural, existe um universo de oportunidades de aprendizagem.

Ao conjunto de instituições com directas responsabilidades na disponibilização de aprendizagens com características formais (aprendizagens organizadas com critério pedagógico,

\footnotetext{
${ }^{1}$ REFERÊNCIA DO PROJECTO No PTDC/CED/81388/2006 “Arqueologia” das Aprendizagens no Concelho do Alandroal desenvolvido pelo Centro de Investigação em Educação e Psicologia (CIEP) da Universidade de Évora e financiado pela Fundação para a Ciência e Tecnologia (FCT).
} 
recorrendo a dispositivos didácticos apropriados e conferindo certificação académica e/ou profissional), teremos, sempre, que adicionar um outro conjunto, bem mais complexo e rico, de instituições e contextos locais gerador de aprendizagens de âmbito não-formal (aprendizagens que não conferem certificação, mas que possuem um grau razoável de organização e intencionalidade) e informal (que ocorrem nos ambientes quotidianos próprios da malha de relações sociais e familiares existente em cada realidade comunitária de residência, trabalho ou convívio).

O território é, neste âmbito, um elemento estruturante de todas as dinâmicas sociais que nele se geram e desenvolvem. Esta realidade é particularmente importante em contextos com características mais rurais, uma vez que, como nos refere Ferragolo da Veiga (2005:233):

\footnotetext{
“As duas questões consideradas fundamentais para a compreensão da mudança no meio rural:

(1) uma concepção do espaço que considera a especificidade do seu território, função da sua história acumulada e da constelação de relações sociais, locais e globais;

(2) e uma concepção de actor, com capacidade reflexiva e de acção, que não retira importância à dimensão estrutural, mas que com ela se encontra intimamente associada."
}

O conhecimento desta rede local de instituições e contextos promotores de oportunidades de aprendizagem é essencial para a cartografia completa da realidade educativa de um território (Imaginário, 2007:27), para lá de nos proporcionar uma perspectiva sobre o grau de mobilização das comunidades para a prática associativa (Lima \& Erasmie, 1982:132). Naturalmente, este exercício conceptual assume o pressuposto de que as dimensões geográfica, demográfica, social, económica e social condicionarão a geometria do mapa das aprendizagens de cada território. Um mapa onde todos os nós da rede se deverão considerar, porque todos eles são, na realidade, coordenadas por onde passam os indivíduos nas suas trajectórias vitais (Nico, 2008:14). Até porque, no presente, “a hegemonia da forma escolar e o monopólio educativo da escola têm vindo a ser postos em causa no domínio dos princípios (concepção de educação permanente) mas também no domínio das práticas" (Canário, 1996:7).

Se considerarmos que todo "o acto educativo está imerso num determinado contexto, que é a síntese de factores como o tempo, o espaço, a história, as experiências, os projectos e as circunstâncias naturais em que se desenvolvem os agentes da prática educativa" (Gómez, Freitas \& Callejas, 2007:177), o estudo e a consideração do potencial educativo dos territórios é, na actualidade, uma das preocupações fundamentais no desenho e concretização de políticas locais promotoras de um modelo de desenvolvimento humano, cultural, económico e social assente numa matriz de sustentabilidade e de estreitamento do trabalho cooperativo, alicerçado em parcerias sinérgicas e potenciadoras dos recursos endógenos. 
O conceito de Cidade Educadora, incorporando este pensamento, aponta, na realidade, para a promoção de territórios geradores e promotores de boas condições para o exercício, com boa qualidade, do Direito à Educação, por parte dos indivíduos neles residentes ou neles intervenientes. É neste novo contexto que os territórios locais se assumem, também, como espaços de "relegitimação da acção pública” (Ferreira, 2005:102).

Com a implementação dos processos de RVCC (Reconhecimento, Validação e Certificação de Competências), desde o ano 2000, foi possível começar a ter uma percepção mais clara da importância relativa das instituições e contextos locais no conjunto de aprendizagens concretizadas pelos indivíduos adultos, ao longo dos respectivos percursos vitais. Na realidade, ao basear-se numa matriz de abordagem em que as histórias de vida assumem um papel determinante - é através desta abordagem que se constroem os denominados portefólios reflexivos, nos quais se identificam as aprendizagens significativas para a construção/desenvolvimento das competências que, mais tarde, serão objecto de reconhecimento e certificação -, tem vindo a ser possível ter uma noção mais aproximada do que é a verdadeira importância da acção educadora das instituições locais das mais diferentes naturezas: empresas, associações de desenvolvimento, desportivas, de solidariedade, culturais, recreativas, juvenis e de âmbito religioso. Até, porque, como nos refere Arroteia et al (2000:157):

"a designação de mapa educativo contempla a existência de outros espaços educativos, que não só a escola, facto que não deve deixar de ser encarado, na actualidade."

A família e a rede de relações sociais são outros elementos fundamentais deste mapa das aprendizagens de cada indivíduo e o seu contributo para a respectiva qualificação está hoje mais visível no conteúdo dos portefólios reflexivos, que têm vindo a ser construídos por centenas de milhares de portugueses.

\section{O ESTUDO DO TERRITÓRIO DO ALANDROAL}


Foi com base nos pressupostos anteriormente referidos que, em 2007, uma equipa de investigação do CIEP (Centro de Investigação em Educação e Psicologia da Universidade de Évora) iniciou o estudo de um determinado território: o concelho do Alandroal.

O concelho alandroalense tem uma área de $544,86 \mathrm{~km}^{2}$ e uma população adulta (com 18 ou mais anos) de 5582 indivíduos recenseados. É constituído por seis freguesias: Nossa Senhora da Conceição (1570 indivíduos), Santiago Maior (2172), São Pedro/Terena (757) São Brás dos Matos/Mina do Bugalho (353), Santo António/Capelins (585) e Nossa Senhora do Loreto/ Juromenha (145).

A pesquisa (primeira fase) foi desenhada e concretizada, de acordo com a sequência indicada na Tabela seguinte:

Tabela 1 - Calendarização das principais fases da concretização do projecto de investigação

\begin{tabular}{|c|c|c|c|}
\hline $\begin{array}{c}\text { Janeiro/Fevereiro } \\
\text { (2008) }\end{array}$ & Março a Junho & Junho & Julho a Outubro \\
\hline $\begin{array}{l}\text {-contactos } \\
\text { institucionais } \\
\text {-divulgação do } \\
\text { projecto no } \\
\text { território } \\
\text {-estabelecimento } \\
\text { de parcerias } \\
\text {-definição da } \\
\text { metodologia a } \\
\text { seguir em cada } \\
\text { freguesia }\end{array}$ & $\begin{array}{l}\text { - cartografia } \\
\text { institucional do } \\
\text { território } \\
\text { - construção de } \\
\text { instrumentos de } \\
\text { recolha de } \\
\text { informação (QAI- } \\
\text { Questionários de } \\
\text { Aprendizagens } \\
\text { Institucionais) }\end{array}$ & $\begin{array}{l}\text {-concretização } \\
\text { experimental da } \\
\text { metodologia e } \\
\text { dos } \\
\text { instrumentos na } \\
\text { freguesia de } \\
\text { Juromenha }\end{array}$ & $\begin{array}{l}\text {-trabalho de } \\
\text { campo (aplicação } \\
\text { de questionários } \\
\text { QAI em cada uma } \\
\text { das freguesias) } \\
\text {-construção de } \\
\text { base de dados } \\
\text { para posterior } \\
\text { análise da } \\
\text { informação }\end{array}$ \\
\hline
\end{tabular}

Para garantir adequadas condições de concretização da pesquisa, foram estabelecidos protocolos com as autarquias locais (Câmara Municipal e Juntas de Freguesia), o Instituto do Emprego e Formação Profissional - Delegação Regional do Alentejo e o Agrupamento de Escolas do Alandroal. Desde o início do projecto, o município disponibilizou, ao projecto de investigação, um gabinete no Fórum Cultural Transfronteiriço e uma técnica superior a tempo inteiro, com formação académica adequada aos objectivos do projecto.

Entre Junho e Outubro de 2008, uma equipa de investigadores (que integrou os autores desta comunicação, estudantes da Universidade de Évora e jovens do concelho do Alandroal) esteve no terreno e aplicou o QAI ao universo de instituições locais (considerando-se instituição toda a pessoa colectiva devidamente identificada fiscalmente). 


\section{OS RESULTADOS DISPONÍVEIS (DIMENSÃO INSTITUCIONAL)}

Da aplicação do QAI, em todas as freguesias do concelho do Alandroal, foi possível, à data desta comunicação, chegar às seguintes conclusões:

i) Foram identificadas 328 instituições, das quais foram inquiridas 281, em todo o concelho do Alandroal, de acordo com a distribuição que se apresenta na seguinte tabela:

Tabela 2 - Número de instituições, por freguesia

\begin{tabular}{|l|c|c|}
\hline \multicolumn{1}{|c|}{ Freguesia } & $\mathbf{N}^{\mathbf{0}}$ de instituições identificadas & \multicolumn{1}{c|}{$\begin{array}{c}\mathbf{N}^{\mathbf{0}} \text { de instituições } \\
\text { inquiridas }\end{array}$} \\
\hline Nossa Senhora da Conceição & 119 & 105 \\
\hline Santiago Maior & 101 & 82 \\
\hline São Pedro/Terena & 45 & 39 \\
\hline $\begin{array}{l}\text { São Brás dos Matos/Mina do } \\
\text { Bugalho }\end{array}$ & 32 & 26 \\
\hline Santo António/Capelins & 18 & 17 \\
\hline $\begin{array}{l}\text { Nossa Senhora do } \\
\text { Loreto/Juromenha }\end{array}$ & 13 & 12 \\
\hline \multicolumn{1}{c|}{ Total } & $\mathbf{3 2 8}$ & $\mathbf{2 8 1}$ \\
\hline
\end{tabular}

ii) Foram assumidas, como aprendizagens institucionais, todas as oportunidades de aprendizagem (de qualquer âmbito de formalidade) construídas e/ou disponibilizadas pelas instituições inquiridas, no período em estudo (19972007)

iii) Foram identificadas 656 aprendizagens no universo de instituições inquiridas (281), de acordo com a distribuição que se apresenta, em seguida:

Tabela 3 - Número de aprendizagens, por freguesia

\begin{tabular}{|l|c|c|c|}
\hline \multicolumn{1}{|c|}{ Freguesia } & $\begin{array}{c}\text { № de instituições } \\
\text { inquiridas }\end{array}$ & $\begin{array}{c}\text { № de } \\
\text { aprendizagens } \\
\text { identificadas }\end{array}$ & $\begin{array}{c}\text { № de Habitantes } \\
\text { Adultos }\end{array}$ \\
\hline $\begin{array}{l}\text { Nossa Senhora da } \\
\text { Conceição }\end{array}$ & 105 & 248 & 1570 \\
\hline Santiago Maior & 82 & 237 & 2172 \\
\hline São Pedro/Terena dos & 39 & 69 & 353 \\
\hline $\begin{array}{l}\text { São Brás do } \\
\text { Matos/Mina } \\
\text { Bugalho }\end{array}$ & 26 & 25 & \\
\hline
\end{tabular}




\begin{tabular}{|c|c|c|c|}
\hline $\begin{array}{l}\text { Santo } \\
\text { António/Capelins }\end{array}$ & 17 & 30 & 585 \\
\hline $\begin{array}{l}\text { Nossa Senhora do } \\
\text { Loreto/Juromenha }\end{array}$ & 12 & 47 & 145 \\
\hline Total & $\mathbf{2 8 1}$ & $\mathbf{6 5 6}$ & $\mathbf{5 5 8 2}$ \\
\hline
\end{tabular}

iv) A freguesia de Juromenha/Nossa Senhora do Loreto revelou-se como o contexto territorial com maior taxa de aprendizagem (considerando o número de aprendizagens identificadas relativamente ao número de instituições inquiridas e de indivíduos residentes), pese embora seja aquela que menor número de habitantes e de instituições evidencia;

v) A freguesia de São Brás dos Matos revelou-se como o contexto territorial com menor taxa de aprendizagem disponível (de acordo com o mesmo critério referido anteriormente), tendo sido a única em que o número de aprendizagens institucionais apurado é inferior ao número de instituições existentes;

\section{CONCLUSÃO}

No momento em que o actual projecto de investigação se encontra, entendemos que a realidade, que já foi possível conhecer, se revelou um interessante objecto de estudo, com evidentes potencialidades de exploração. De facto, o universo de instituições existentes superou, em grande medida, as expectativas iniciais e o conjunto de aprendizagens identificadas está, claramente, para lá do que seria imaginável, no início deste percurso.

Temos, hoje, a clara percepção de que a análise - que está em curso - às aprendizagens identificadas nos revelará um universo, ainda pouco conhecido, de contextos não-formais e informais de educação e promotor de um contributo muito significativo no processo de qualificação dos indivíduos residentes no concelho do Alandroal.

Atendendo às, já, evidentes diferenças existentes entre as várias freguesias do concelho, ao nível da taxa de qualificação institucional, é de esperar que as aprendizagens concretizadas pela população residente em cada contexto revelem, consequentemente, padrões diversos.

Uma certeza, no entanto, poderá já ser assumida: sendo o território um factor determinante no processo de qualificação dos indivíduos e das instituições, é fundamental que, em cada contexto territorial, se proceda a uma adequada cartografia de todas as aprendizagens existentes. Sem este exercício, conceptual e institucionalmente, alargado e rigoroso, não será 
possível a construção de um verdadeiro mapa educacional, enquanto verdadeiro e participado instrumento de apoio à gestão local e regional da Educação e da Formação.

\section{REFERÊNCIAS BIBLIOGRÁFICAS}

Arroteia, J. e tal (2000). Gafanha da Nazaré: escola e comunidade numa sociedade em mudança. Lisboa: Instituto de Inovação Educacional

Canário, R. (1996). "Nota de Apresentação". in Natália Alves et al. A escola e o espaço local: políticas e actores. Lisboa: Instituto de Inovação Educacional

Ferragolo da Veiga, J. (2005). Território e Desenvolvimento Local. Oeiras: Celta Editora

Ferreira, F. (2005). O Local em Educação: animação, gestão e parceria. Lisboa: Fundação Calouste Gulbenkian

Gómez, J., Freitas, O. \& Callejas, G. (2007). Educação e Desenvolvimento Comunitário: perspectivas pedagógicas e sociais da sustentabilidade. Porto: Profedições

Lima. L. \& Erasmie, T. (1982). Inquérito às Associações do Distrito de Braga. Braga: Unidade de Educação de Adultos da Universidade do Minho

Nico, B. (2008). “Aprender no Interior português: Vértices para um pensamento integrado e uma acção responsável”. in Bravo Nico (Org.). Aprendizagens do Interior: reflexões e fragmentos. Mangualde: Edições Pedago 